\title{
Qualification of Soft Costs of the US Federal Guidance When Considering Greenhouse Gas Emissions and the Effects of Climate Change in NEPA Reviews
}

\author{
Maria Angelica Deeb \\ Transportation Department, City of Mesa, Mesa, AZ, USA \\ Email: Maria.Deeb@mesaaz.gov
}

Received 29 May 2015; accepted 21 August 2015; published 25 August 2015

\begin{abstract}
A notice by the Council of Environmental Quality (CEQ) was published on December 14, 2014 regarding the revised "Draft Guidance for Federal Departments and Agencies on Consideration of Greenhouse Gas Emissions and the Effects of Climate Change in NEPA Reviews". The review of this 2014 draft guidance suggested increased analysis, work, review and approvals required by the State Department of Transportation (DOT) and Federal Highway Administration (FHWA) working with and on behalf of local public agencies (LPAs) in order to authorize and obligate roadway projects funded with federal-aid money. All federal-aid-funded roadway projects require a NEPA analysis to be done on the action (project) and an environmental clearance document to be obtained prior to finalizing the design. The 2014 draft guidance may complicate an already lengthy and often critical path activity for roadway projects requiring NEPA documentation.
\end{abstract}

\section{Keywords}

NEPA Documents, Greenhouse Gas Emissions, Climate Change, Transportation, Roadway, Local Public Agencies

\section{Introduction}

A notice by the Council of Environmental Quality (CEQ) was published on December 14, 2014 regarding the revised "Draft Guidance for Federal Departments and Agencies on Consideration of Greenhouse Gas Emissions and the Effects of Climate Change in NEPA Reviews" [1].

Projects that are built by the transportation sector with federal-aid funds require permits or clearances from federal agencies [2] (such as Federal Highway Administration (FHWA)), therefore, are subject to review under the National Environmental Policy Act [3] (NEPA).

A key finding of this research paper concludes that members of Local Public Agencies (LPAs), such as the City of Mesa, Arizona, are currently working with the Arizona Department of Transportation (Arizona DOT) in 
ensuring the implementation of NEPA and ensuring the achievement of the NEPA goals consistently with established regulations and case law. However, this process may become more complicated and lengthy as the rules for review may change related to Green House Gases (GHS) and Climate change. If the proposed 2014 guidance becomes case law, LPAs will need to make sure that before the enforcement of the law occurs, State DOTs and FHWA clarify the 2014 guidance-case law. Also, these clarifications must define the scope of the NEPA statute and CEQ's implementing regulations related to GHG. Making this a challenge and a real cost for the process is the unique nature of GHG emissions and climate, as these present more different considerations than any other environmental issue and must be specific and unique for transportation agencies.

Highlighting other research findings conducted for this paper, it is clear that the CEQ regulation cannot address all projects in all situations as CEQ proposes [4]. As CEQ explains in the Revised Draft Guidance, "GHG emissions from an individual agency action will have small, if any, and potential climate change effects. Government action occurs incrementally, program-by-program, and climate impacts are not attributable to any single action, but are exacerbated by a series of smaller decisions, including decisions made by the Government [5]". Lastly, the contribution of any transportation project with GHG emissions is very small when compared to the atmospheric concentration of GHGs and relative to the GHG emissions from nature. Because of this, and the effects of GHG emissions are global, therefore it is not possible for agencies, or CEQ, to link specifically any transportation federal action to climate change effects.

\section{Method}

Qualitative research was the method of inquiry employed in this research paper. For this paper, the CEQ regulations [6], law review papers [7], and papers describing the NEPA within land use planning [8] were studied. The aim was to gather an understanding of DOT's NEPA document development and approval, and qualify how the new draft guidance of 2014 affects such development. Future research should be conducted when the guidance is formally adopted, and a process for implementing such is developed. The research conducted is only an initial investigation of why and how the guidance may affect NEPA decisions that are arrived while planning, designing and constructing roadway projects. It is also worth noticing that the research only focuses on the NEPA documents developed for transportation projects.

The analysis of qualitative data was observer impression. As an Arizona transportation professional working for a city, I would like to voice my concern, specifically that this guidance is imposing unfunded additional work on the Federal Highway Department (FHWA) and the Arizona Department of Transportation (ADOT). These two agencies have not, to date [9], communicated to the cities which have to implement this guidance, their agencies' position regarding this guidance. There is time between the date when CEQ addresses and responds to all comments received and the date when CEQ implements the guidance; it is the hope of this paper that this time is used by FHWA and ADOT to educate the LPAs. This is just a request for this education to happen sooner rather than later because city practitioners cannot environmentally clear any of our federally aid funded roadway projects as we depend on ADOT to do so. We, LPAs, are responsible for any transportation project constructed in our cities. We do not have the authority to approve NEPA documents for our transportation projects; therefore we need the state DOT to perform this task and the FHWA to approve the environmental clearance documents. The 2014 GHG and climate change guidance just makes this already lengthy process a more complicated one. This is a real cost to all LPAs that can be quantified once CEQ determines the level of required analysis, and there is an understanding and estimation made on the time required for the process to undergo any public and agency outreach efforts, and additional time required to make it through the DOT and FHWA approvals.

\section{Increased Work for State DOTS?}

\subsection{Climate Change and GHG in NEPA Docs}

The proposed guidance wants all NEPA analysis to discuss climate change and GHG; however, it is recognized that the effects of GHG emissions and climate change have a global character, therefore it is not useful, for NEPA purposes, to link GHG emissions from a proposal to specific climatological changes to a particular site [10]. The revised draft guidance recommends that agencies address GHG emissions and the effects of climate change for all proposed actions. It also recommends that the development of environmental assessments and en- 
vironmental impact statements take GHG emissions and climate change impacts into account.

The above-mentioned effort would result in more work for the state DOTs as it would be required to include in the Categorical Exclusions (CEs) and other NEPA documents (such as the Environmental Assessments-EA, and the Environmental Impact Statements-EIS) a declaration that GHS and climate change have been addressed. In most transportation related project cases, there should be no link to specific changes or actions. Consistency of evaluation and analysis should also be required throughout roadway NEPA analysis. The ultimate goal of the evaluation on climate change and GHG should be not to add more additional work than required and not to impose additional and lengthy review/approval times when not warranted. This researcher suggests the DOTs to consider, including a negative declaration (i.e. no significant negative impact) in the language of all CEs; and this can be done as congestion mitigation is included in almost all roadway projects' scope of work.

\subsection{Project-Level Analyses}

The new proposed guidance is backing off requiring GHG and climate change qualitative and quantitative analysis for all projects. Back in 2010, the comments on the guidance included that climate change is global in nature and the attempt to "qualitatively" link proposed individual project emissions and climate change would be arbitrary and speculative. The 2014 guidance requires agencies to exercise independent judgment and discretion in determining whether and how potential GHG emissions and climate change effects should be disclosed and considered in preparing their NEPA analyses and documentation. For there to be consistency on the manner transportation projects are analyzed in regard to climate change and GHG emissions, it is hoped that the FHWA together with all state DOTs inform LPAs about how this is to be achieved without including much more analysis than the one already done. This should be easy to implement as studies such as the 2008 publication "Growing cooler: the evidence on urban development and climate change [11]" conclude that meaningful $\mathrm{CO}_{2}$ reduction is to be achieved with the reduction in vehicle miles traveled (VMT) as well as the implementation of new development and redevelopment local policies, which include complete streets, deterrents on urban sprawl and the suggestion that further reduction is achieved by having the states implement, together with the federal governments, ways to improve vehicle and fuel technology.

As stated before, all NEPA docs should include language analyzing the project alternatives or GHG and/or climate change-related mitigations. With this, an agency can then document its rationale for not conducting further analysis.

The United States, through the federal government, has defined some GHG emission reduction targets, and it is willing to make those targets part of the international negotiations on climate change. In compliance with the responsibilities the US government has undertaken with the international community, through the United Nations Framework Convention on Climate Change (UNFCCC), the USEPA has to produce a yearly estimate of all GHG emitted, and provide a description of the actions the government has taken to reduce emissions and achieve the targets it has adopted. The contribution to "emission reduction of GHG" from the transportation sector could, in principle, be estimated as the contribution of all federal-funded actions.

\subsection{Qualitative/Quantitative Analyses}

This revised draft guidance gives each agency responsibility for selecting the appropriate level at which to disclose the effects of GHG emissions and climate change, so long as it sets forth a reasoned explanation based on accepted science and whether that information is helpful for decisions. Much more visibility is given to the FHWA and DOTs as they are the ones determining the manner in which this is to be achieved.

\subsection{Guidance Does Not Mean "One Size Fit All."}

The draft guidance should be read and followed with caution. The guidance is the formulation of how transportation practitioners should include the assessment and/or the risk analysis of GHG and climate change in the design of their projects, infrastructure, networks and agencies they represent. Further consideration of how to include GHG emissions and climate change in roadway NEPA documents should take into account the fact that GHG emission "accounting” and climate change impacts are two different analyses that ought to be considered independently [12]. 


\section{Results}

Discussing these issues with a specialist that is currently working for the World Bank and the Inter-American Development Bank, GHG accounting is to assess the potential contribution of the action to the total emissions globally. Some recent analyses indicate that the amount of "remaining" emissions to reach the agreed global threshold of 2 degrees warming is a fixed quantity; therefore each design and/or construction alternative needs only to estimate its contribution. The expectation is that the option selected is the one that contributes fewer GHG emissions to the atmosphere. The prepared NEPA document should document this fact [13].

The other request, independently of the previous one, seeks to make the investment resilient to climate change [14]. The works should incorporate the potential impact of a changing climate on the design and operational life of the investment. More specifically, they should ensure that the LPA project team is aware of some core changes (or expected changes) in climate variables as a consequence of climate change. Arizona may expected more heat waves, and higher summer temperatures. These "environmental parameters" may have a considerable impact on the design of the "components" of a roadway project (signs, paints, posts, and even the surface mix might require adjustments). With precipitation, the considerations are no less important. There is some expectation of more intense precipitation everywhere. That implies that all drainage components ought to incorporate the increase in precipitation intensity in their designs. In the case of Arizona, increased short-duration precipitation and enhanced intensity might bring sedimentation problems that were not common under previous climate conditions. All these considerations seek to make the action resilient to climate change.

In Mr Deeb’s analysis, there is no need to link GHG and climate change impacts. They should be taken separately. But each should be considered as both have important impacts on the final well-being of the community.

\section{Conclusions-Programmatic NEPA Analyses}

Because most local public agencies (LPAs) use programmatic NEPA analyses, it is encouraged that the FHWA, state DOTs and all Metropolitan Planning Organizations (MPOs) consider the use of a metropolitan planning organization, or a regional greenhouse gas analysis, or perhaps even statewide greenhouse gas analysis that may then be incorporated by reference in the NEPA document analysis of GHG emissions and climate change. This kind of information may provide a better perspective on greenhouse gas emissions rather than a specific projectlevel analysis, like a transportation project.

No less important is a concerted effort among federal, state and local agencies to develop 1) climate change scenarios useful for planning purposes (against the alternative of each agency selecting scenarios according to uncoordinated criteria); and 2) guidance on how the scenarios should be used to guide the design of roadways. Such guidance, specific to sub-regions, might provide practitioners with tools to design roadway projects and at the same time facilitate the additional-unfunded-task of reviewing and approving NEPA analyses.

Furthermore, all LPA practitioners should read "Draft Guidance for Federal Departments and Agencies on Consideration of Greenhouse Gas Emissions and the Effects of Climate Change in NEPA Reviews” [15] and discuss it with their MPO and DOTs.

Transportation LPAs should continue to build projects in conjunction with the federal agencies and State DOTs, and ensure together that these implement NEPAs are consistent with established regulations and case law; however, guidance or perhaps a better language in the case law is required.

The CEQ regulation cannot address all projects in all situations as CEQ proposes and because the contribution of any transportation project with GHG emissions is very small when compared to the atmospheric concentration of GHGs and relative to the GHG emissions from nature and because the effects of GHG emissions are global, it is not possible for agencies, or CEQ, to link specifically any transportation federal action to climate change effects. No additional costs (direct and soft costs) should be added to projects requiring NEPA analysis; there should be a NEPA process that is streamlined and more cost effective.

\section{References}

[1] (2014) Revised Draft Guidance. https://www.federalregister.gov/articles/2014/12/24/2014-30035/revised-draft-guidance-for-federal-departments-and-a gencies-on-consideration-of-greenhouse-gas\#h-17

[2] (2008) Subject “Actions” Include Federal Agency Projects, Programs, and Regulations as well as Approvals, Issuance of Permits to, and Funding of Private (Non-Federal) Actions. See 40 C.F.R. $\S \S \quad$ 1508.4, 1508.18(a)-(b) 
[3] (2000 \& Supp. 2005) National Environmental Policy Act of 1969, 42 U.S.C. §§ 4321-4370f.

[4] (2015) ANGA Comments on CEQ’s Revised Draft Guidance for Federal Departments and Agencies on Consideration of GHG Emissions and the Effects of Climate Change in NEPA Reviews.

http://anga.us/media-room/testimony-and-filings/2015/3/25/anga-comments-on-ceq-s-revised-draft-guidance-for-feder al-departments-and-agencies-on-consideration-of-ghg-emissions-and-the-effects-of-climate-change-in-nepa-reviews

[5] 79 Fed. Reg. at 77,825

[6] NEPA establishes the Council on Environmental Quality (CEQ) in the Executive Office of the President to oversee the Act's implementation, to advise the President on the state of the environment, and to make recommendations for achieving NEPA’s goals. Id. §§ 4342, 4344. In this capacity, CEQ has promulgated detailed regulations and issued numerous regulatory guidance documents. See generally 40 C.F.R. ch. V (2008)

[7] Stein, A.L. (2010) Climate Change under NEPA: Avoiding Cursory Consideration of Greenhouse Gases, 81 U. Colo. L. Rev. 473. http://scholarship.law.ufl.edu/facultypub/503

Kass, M.J. (2009) A NEPA-Climate Paradox: Taking Greenhouse Gases Into Account in Threshold Significance Determinations. Indiana Law Review, 42, 47. Thomas Jefferson School of Law Research Paper No. 1380583.

http://ssrn.com/abstract $=1380583$

Karkkainen, B.C. (2002) Toward a Smarter NEPA: Monitoring and Managing Government's Environmental Performance. Columbia Law Review, 102, 903. http://dx.doi.org/10.2307/1123648

[8] Salkin, P.E. (2009) Sustainability and Land Use Planning: Greening State and Local Land Use Plans and Regulations to Address Climate Change Challenges and Preserve Resources for Future Generations. William \& Mary Environmental Law and Policy Review.

[9] July 16, 2015

[10] 79 Fed. Reg. at 77,825

[11] Ewing, R.H. and Anderson, G. (2008)

[12] Intergovernmental Panel on Climate Change (2015) Climate Change 2014: Synthesis Report. IPCC Fifth Assessment Report.

[13] Deeb, A.M. (2015) Personal Interview.

[14] Deeb (2015)

[15] https://www.federalregister.gov/articles/2014/12/24/2014-30035/revised-draft-guidance-for-federal-departments-and-a gencies-on-consideration-of-greenhouse-gas\#h-17 